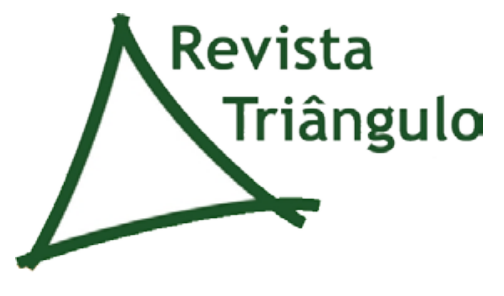

Uberaba, v. 5, n. 2, p. 22-44, jul./dez. 2012. ISSN: 2175-1609

\title{
O GÊNERO MULTIMODAL CHARGE E SUA ARTICULAÇÃO COM O ENSINO DE LÍNGUA PORTUGUESA: PROPOSIÇÕES DIDÁTICAS
}

\author{
THE MULTIMODAL GENRE CHARGE AND ITS RELATIONSHIP TO THE \\ PORTUGUESE LANGUAGE TEACHING: DIDACTIC PROPOSITIONS
}

Alex Caldas Simões ${ }^{1}$, Maria Carmen Aires Gomes ${ }^{2}$

\footnotetext{
${ }^{1}$ Professor universitário e pesquisador das ciências da linguagem. Mestre em Letras pela Universidade Federal de Viçosa (UFV) e graduado em Letras (Licenciatura em Língua Portuguesa e Bacharelado em Estudos Linguísticos) pela Universidade Federal de Ouro Preto (UFOP), tem se dedicado a configuração de gêneros discursivos, ao estudo das relações gênero/suporte e ao ensino de língua materna. E-mail: axbr1@yahoo.com.br

${ }^{2}$ Pós-Doutora em Estudos da Linguagem e Linguística Aplicada pela Pontifícia Universidade Católica de São Paulo (PUC-SP) e Professora Associada I do Departamento de Letras da Universidade Federal de Viçosa (UFV). Doutora e Mestra em Estudos Linguísticos/Análise do Discurso pela Universidade Federal de Minas Gerais (UFMG).E-mail: mcgomes@ufv.br
} 


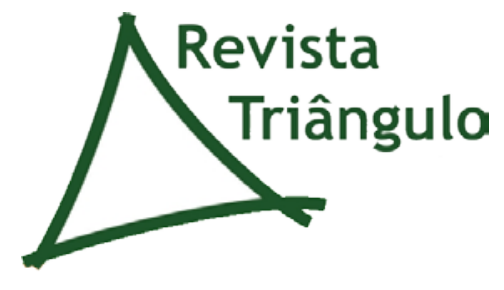

Uberaba, v. 5, n. 2, p. 22-44, jul./dez. 2012. ISSN: 2175-1609

\title{
RESUMO
}

Em nossa exposição, apresentaremos a teoria sistêmico-funcional proposta por Hasan (1989) como forma de instrumentalizar os professores de língua portuguesa para o trabalho com os gêneros multimodais em sala de aula. A partir de Simões (2010), apresentaremos a configuração do gênero charge - depreendida da análise de um corpus de 20 exemplares de charges de autoria de Júlio Erthal, contidas no livro Fatores de Risco (1998) - e como este pode ser trabalhado em aulas de língua materna. Ao apresentarmos aos alunos a Estrutura Potencial do Gênero (EPG), indicamos ao professor o que ensinar do gênero quando trabalhar com a charge (seus estágios obrigatórios) e como instrumentalizar esse gênero no ensino de língua materna (evidenciando a sua configuração na EPG). Tendo em vista essa assertiva teórica, construímos nossas proposições didáticas para o ensino de língua portuguesa com o gênero charge. Nossa proposição didática consiste na apresentação de conceitos-chave da teoria de gêneros para os alunos; na pesquisa orientada sobre o gênero, por meio de um roteiro de perguntas direcionado; na exposição simplificada da Estrutura Potencial do Gênero (EPG); e na resolução de exercícios que fixem o entendimento dos estágios obrigatórios do gênero.

Palavras-chave: Gêneros Multimodais. Charge. Linguística Sistêmico-Funcional (LSF). Estrutura Potencial do Gênero (EPG). Ensino de Língua Portuguesa.

\begin{abstract}
In our exposure we present the systemic-functional theory proposed by Hasan (1989) as a way of exploiting the Portuguese language teachers to work with multimodal genres in the classroom. From Simões (2010) present the configuration of genre charge - inferred from the analysis of a corpus of 20 samples of charge authored by Julius Erthal contained in the book Risk Factors (1998) - and how this can be worked into lessons mother tongue. In presenting students with the Generic Structure Potential (GSP) we indicate the teacher to teach the genre when working with the charge (obrigatory elements) and as tool for this kind of mother tongue in teaching (showing its configuration in GSP). Given this theoretical assertion, build our propositions to the didactic teaching of Portuguese language with the genre charge. Our proposition consists of didactic presentation of key concepts of the theory of genres for students; oriented research on the genre through a script of questions targeted, in simplified exposition of GSP, and in solving exercises which set the understanding of required internships in the genre.
\end{abstract}

Keywords: Multimodal Genre. Charge. Systemic Functional Linguistics (SFL). Generic Structure Potential (GSP). Teaching Portuguese Language. 


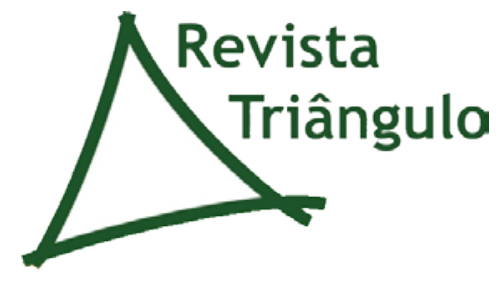

Uberaba, v. 5, n. 2, p. 22-44, jul./dez. 2012. ISSN: 2175-1609

\section{INTRODUÇÃO}

Já não é novidade que hoje o ensino de língua materna tem se direcionado para o ensino do texto em sala de aula, materializado em algum gênero do discurso (Cf. PCN, 1998). Tal postulação vem instigando diversos pesquisadores, das mais diversas áreas de estudo do objeto, a investigar a questão: como levar os gêneros discursivos para a sala de aula? Como ensinar língua portuguesa tomando como diretriz o estudo dos (com os) gêneros (Cf. SOARES, 2009)?

Atualmente, devido à profusão dos estudos multimodais, ainda podemos nos questionar: como ensinar tomando como diretriz os gêneros multimodais ${ }^{3}$ ? Afinal, que tipo de estratégias, teorias e métodos podem ser utilizados quando resolvemos instrumentalizar os gêneros multimodais no ensino de língua portuguesa?

Em nossa pesquisa, mostraremos alguns pressupostos da teoria Linguística SistêmicoFuncional (Cf. HASAN, 1989; 2005) como forma de instrumentalizar os professores de língua portuguesa para o trabalho com os gêneros em sala de aula. A fim de cumprir nossos objetivos, apresentaremos, a partir de Simões (2010), a configuração do gênero charge ${ }^{4}$, ao depreendermos a Estrutura Potencial do Gênero (EPG) de 20 charges de Júlio Erthal, extraídas do livro Fatores de Risco, de 1998. De posse dessa configuração, apresentaremos, por fim, algumas estratégias de ensino de língua portuguesa com o gênero charge, chamadas por nós de proposições didáticas. Ao final dessa discussão, apontaremos nossas conclusões finais sobre o assunto, mostrando algumas implicações e alcances de nossas exposições.

\footnotetext{
${ }^{3}$ Podemos entender multimodalidade como sendo os textos "nos quais mais de uma modalidade converge em uma situação para produzir significado. O canal lingüístico em textos multimodais pode ser falado ou escrito ou qualquer combinação desses e de outros modos semióticos implantado pode ser físico ou visual ou qualquer combinação desses” (BOWCHER, 2007, p. 630 - tradução nossa).

${ }^{4}$ As discussões referentes a Júlio Erthal e à Estrutura Potencial do Gênero charge pertencem a um dos núcleos de discussão de nossa dissertação de mestrado.
} 


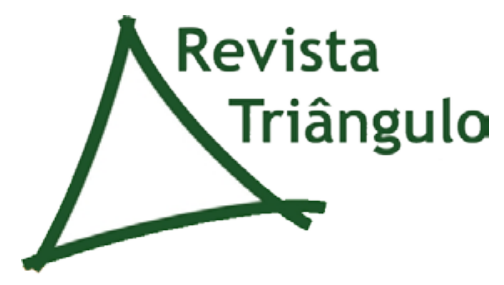

Uberaba, v. 5, n. 2, p. 22-44, jul./dez. 2012. ISSN: 2175-1609

\section{A POSTULAÇÃO SISTÊMICO-FUNCIONAL DE ANÁLISE DE GÊNEROS DE RUQAYIA HASAN}

Hasan (1989) procura em suas pesquisas demonstrar que o contexto é um elemento importante na análise/compreensão de qualquer texto. Para Hasan (1989; 2005), por meio das singularidades do contexto, podemos prever os elementos da estrutura de um texto, ou seja, quais elementos devem ocorrer (seus estágios obrigatórios), quais podem ocorrer (seus estágios opcionais), e quais podem ocorrer com certa frequência (seus estágios eletivos ou recursivos).

A fim de instrumentalizar essa postulação, a pesquisadora (1989) propõe o conceito de Configuração Contextual (ou CC), que pode ser entendido aqui como um conjunto específico de valores realizados pelo registro - ou contexto de situação - constituído por: campo, relação e modo. Por meio da expressão verbal de uma configuração contextual (CC), configuramos, então, a Estrutura Potencial de um Gênero (EPG). A EPG corresponde a um instrumento discursivo bastante produtivo, pois, por meio dela, expressam-se possibilidades estruturais de um texto em uma dada situação, ou seja, seus estágios obrigatórios, opcionais e recursivos.

Com intuito de ilustrar a sua exposição, Hasan (1989), ao se referir à Estrutura Potencial de Gênero (EPG), apresenta alguns sinais gráficos que auxiliam os pesquisadores na exposição de uma EPG. A partir de Hasan (1989) e Eggins (1994), apresentamos abaixo alguns sinais gráficos utilizados pela proposta Sistêmico-Funcional para expressar a EPG:

Figura 1: Sinais gráficos de representação da EPG

$\wedge$ = Seqüência;

* = Estágio Obrigatório, porém não ocorre sempre na mesma ordem;

( ) = Estágios Opcionais;

$\downarrow=$ Estágios Recursivos;

$\downarrow\{\}=$ Estágios Recursivos, na ordem fixa estabelecida entre chaves.

Fonte: os autores. 


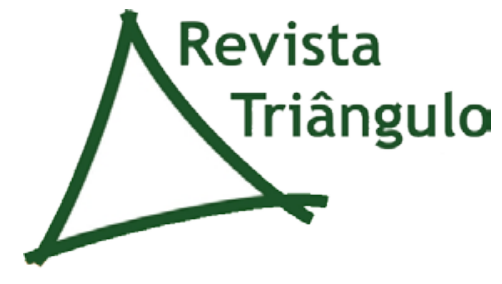

Uberaba, v. 5, n. 2, p. 22-44, jul./dez. 2012. ISSN: 2175-1609

Vale ressaltar ainda que Hasan (1989; 2005) não define a noção de gênero em sua pesquisa, mas evidencia que este pode ser pensado a partir da noção de registro. Dessa forma, do registro (campo, relação e modo/contexto de situação) emergem valores específicos (Configuração Contextual - CC) que se expressam verbalmente por meio de estágios, em especial os obrigatórios, que é o que define um gênero discursivo.

Tomando as palavras de Hasan, podemos dizer que:

- “[u]m gênero é conhecido pelos significados associados a ele” (HASAN, 1989, p. 108);

- “[o]s gêneros têm uma relação lógica com a CC, sendo sua expressão verbal. Se a CC é uma classe de tipos de situação, então gênero é linguagem fazendo o trabalho apropriado para aquela classe de acontecimentos sociais” (HASAN, 1989, p. 108);

- $\quad$ "[g]êneros podem variar sutilmente da mesma maneira que o contexto. Mas para o mesmo dado texto pertencer a um mesmo gênero específico, sua estrutura deve ter alguma possibilidade de realização na dada EPG” (HASAN, 1989, p. 108);

- $\quad$ "[...] os textos pertencentes ao mesmo gênero podem variar em sua estrutura, o que eles não podem variar sem consequiências para a sua atribuição genérica são os elementos obrigatórios e sua disposição na EPG” (HASAN, 1989, p. 108).

Cabe salientar que a teorização proposta por Hasan (1989) foi destinada à análise de textos verbais e não de textos não verbais. Diante desse fato, seria comum afirmar que a teorização da autora não poderia abarcar a análise de textos não verbais (ou multimodais). Entretanto, isso não é dito. Apesar de ser proposta para a análise de textos verbais, nos parece que tal aporte não impede a análise de elementos não verbais, como a linguagem dos quadrinhos (Cf. RAMOS, 2007; 2009; 2011), por exemplo. Como acreditamos, a Estrutura Potencial do Gênero (EPG) idealizada por Hasan (1989) é depreendida do contexto de situação (registro) e este se materializa por elementos significativos, sejam eles verbais ou não verbais. É por meio desse pressuposto que é possível analisar gêneros multimodais, uma vez que todos os elementos do texto concorrem para a materialização do gênero.

A partir de nossa experiência (Cf. SIMÕES, 2010), analisamos os gêneros multimodais que utilizam a linguagem dos quadrinhos (Cf. RAMOS, 2007; 2009; 2011). Essa análise se tornou possível por meio das teorizações teórico-metodológicas proposto pela autora (1989; 2005), uma vez que essa linguagem já foi codificada e, portanto, pôde ser quantificada em relação à sua recorrência e funcionalidade no texto. 


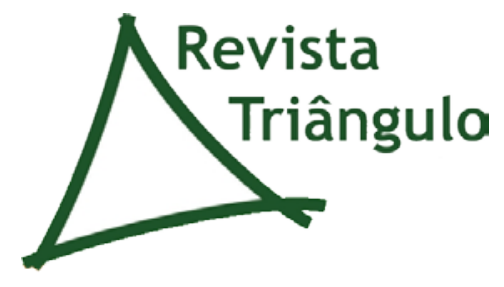

Uberaba, v. 5, n. 2, p. 22-44, jul./dez. 2012. ISSN: 2175-1609

Apresentaremos, na seção seguinte, a configuração do gênero multimodal charge ${ }^{3}$, tal como produzida por Júlio Erthal na obra Fatores de Risco, publicada em 1998 pela editora Ediouro.

\section{AS CHARGES DE JÚLIO ERTHAL EM FATORES DE RISCO}

Júlio Erthal é caricaturista e veio a se consagrar como chargista no jornal O Globo. Como artista, ganhou três Salões Nacionais de Humor e já teve os seus desenhos publicados nas revistas Pasquim, Veja, Época e Manchete. O autor ainda se dedica à produção de animações, como as vinhetas da Rede Globo.

Das obras do autor, selecionamos o livro de charges e caricaturas Fatores de Risco (1998) - recuperamos da obra somente a parte das charges -, que faz uma retrospectiva do governo presidencial de Fernando Henrique Cardoso no Brasil (1994 a 1998) passando pela Copa do Mundo da França e os escândalos políticos, como o caso do ex-presidente dos Estados Unidos, Bill Clinton, e sua secretária. Nas palavras do autor, podemos dizer que essa obra

\footnotetext{
“[é] um breve apanhado de alguns dos fatos mais caricaturáveis no período: uma viagem que começa com o surgimento do Real e termina na REI-leição, passando pelo [sic] remédios falsificados e políticos idem, pela crise das bolsas e dos bolsos, pelo desaPENTAmento na Copa da França e pelas estrepolias sexuais do presidente Clinton.” (ERTHAL, 1998, seção introdução).
}

Gostaríamos de chamar a atenção para o fato de o gênero charge ser bastante confundido com outros gêneros multimodais, tais como o cartum, a tira cômica e a caricatura (Cf. SIMÕES, 2010). Sendo assim, fica cada vez mais clara a necessidade de se configurar gêneros no ensino de línguas para tentar evitar confusões terminológicas, de conteúdo, finalidade e outras. Entendemos, portanto, que configurar gêneros é uma atividade sine qua non para a instrumentalização dos gêneros no ensino de língua materna (Cf. SIMÕES, 2011). É por esse motivo que na próxima seção configuraremos o gênero charge, como forma de entender melhor o seu funcionamento semântico, discursivo e textual. Após essa configuração, apresentaremos nossas estratégias de ensino de língua portuguesa que contemplam o gênero multimodal charge. 


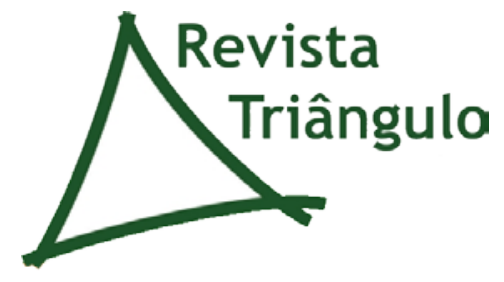

Uberaba, v. 5, n. 2, p. 22-44, jul./dez. 2012. ISSN: 2175-1609

\section{A ESTRUTURA POTENCIAL DO GÊNERO MULTIMODAL CHARGE}

\subsection{CONTEXTO DE SITUAÇÃO (REGISTRO)}

O Contexto de Situação do gênero multimodal charge é estruturado por: (a) um campo, onde há uma argumentação imagética retextualizada ${ }^{5}$ de uma notícia jornalística ${ }^{6}$, com vistas à divulgação de uma opinião sobre um fato social relevante; (b) uma relação, identificada como autor (chargista, produtor da argumentação imagética retextualizada) e leitor (interessado em argumentações por meio de imagens); e (c) um modo, identificado como uma linguagem escrita construída a partir da associação de imagens e textos.

\subsection{CONTEXTO DE CULTURA (GÊNERO)}

A Estrutura Potencial do Gênero (EPG) configurada da charge pode ser assim descrita

Figura 2: Estrutura Potencial do Gênero (EPG) charge

$$
\begin{aligned}
& \text { Retx } \left.\left.\left.{ }^{*} B\right\lrcorner \wedge \text { On }\right\lrcorner^{\wedge} \text { Lt }\right\lrcorner \wedge \text { (Tit) } \wedge(\text { C })^{\wedge} \\
& (\text { Intergn })^{\wedge}(\text { Sar })^{\wedge}(\text { Rq })^{\wedge}(\text { Cen })^{\wedge}(\text { S })^{\wedge} \mathbf{D t v}^{\wedge} \\
& \text { Aau* }^{*}
\end{aligned}
$$

Fonte: SIMÕES, 2010, p. 86.

\footnotetext{
${ }^{5}$ A retextualização é um processo linguístico-discursivo que pode ser conceituado como: a "[...] refacção ou a reescritura de um texto para outro, ou seja, trata-se de um processo de transformação de uma modalidade textual em outra, envolvendo operações específicas de acordo com o funcionamento da linguagem” (DELL’ ISOLA, 2007, p. 36). Mais especificamente, podemos dizer que a charge é um produto essencialmente retextualizado, em que se passa de uma notícia jornalística para um texto imagético argumentativo.

6 "Poder-se-ia definir, ainda, a notícia jornalística como 'informação atual, verdadeira, carregada de interesse humano e capaz de despertar a atenção e a curiosidade de grande número de pessoas'.” (AMARAL, 1978, p. 60). Vale ressaltar que a notícia será compreendida como um instrumento e não como um gênero discursivo, dessa forma, ela está presente em outros gêneros discursivos além da notícia, como, por exemplo, a reportagem ou a entrevista.
} 


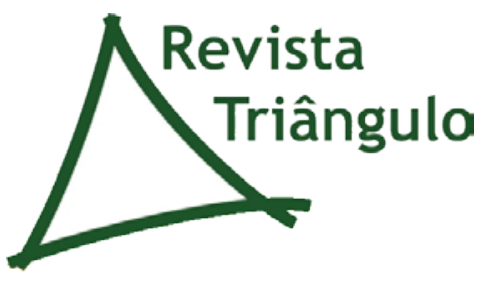

Uberaba, v. 5, n. 2, p. 22-44, jul./dez. 2012. ISSN: 2175-1609

Em que:

Tabela 1: Siglas da EPG e delimitação de estágios da charge

\begin{tabular}{|l|l|}
\hline Estágios Obrigatórios & $\begin{array}{l}\text { (1) Retextualização (Retx) } \\
\bullet \quad \text { Notícia jornalística (Nj) }\end{array}$ \\
& $\begin{array}{l}\bullet \quad \text { Argumentação (Arg) } \\
\text { (2) Data de veiculação (Dtv) } \\
\text { (3) Assinatura autoral (Aau) }\end{array}$ \\
\hline Estágios Opcionais $^{7}$ & $\begin{array}{l}\text { (1) Título (Tit) - (2) Cor (C) - (3) Sargeta (Sar) - (4) Requadro (Rq) } \\
\text { (5) Cenário (Cen) - (6) Seriação (S) - (7) Intergenericidade (Intergn) }\end{array}$ \\
\hline $\begin{array}{l}\text { Estágios recursivos } \\
\text { (ou iterativos) }\end{array}$ & (1) Balão (B) - (2) Onomatopéia (On) - (3) Linhas e traços (Lt) \\
\hline
\end{tabular}

Fonte: Adaptado de Simões (2010, p. 86)

Por questões metodológicas e de formatação do artigo, discorreremos aqui somente sobre os estágios obrigatórios, aqueles que, segundo Hasan (1989; 2005), definem um gênero do discurso, no nosso caso, o gênero charge. Outros detalhes podem ser vistos em Simões (2010). Dessa forma, temos os seguintes estágios obrigatórios: retextualização, data de veiculação $e$ assinatura autoral.

O primeiro elemento, a retextualização, tem por finalidade ressaltar, de forma imagética, uma opinião sobre alguma notícia jornalística de nosso cotidiano. Dentre as características desse estágio, temos que:

- a charge é um produto do processo de retextualização. Normalmente, origina-se de uma notícia jornalística que é transposta para um texto imagético de cunho argumentativo, notadamente crítico ou irônico. Sendo assim, a charge acaba se constituindo pelos mesmos elementos da notícia: atualidade, veracidade e interesse. Todo gênero jornalístico, dessa forma, possui uma notícia/fato a ser relatada. Dessa forma, a retextualização para a charge pode ocorrer de artigo de opinião, entrevista, nota, notícia, reportagem, frase etc. (Fig. 4);

- o conteúdo retratado na notícia normalmente é conservado. Ou seja, mantêm-se: personalidades, ações, eventos, situações etc. Apesar disso, apresenta-se uma informação nova, argumentativa, que revela a posição do chargista diante dos fatos noticiados. Essa 


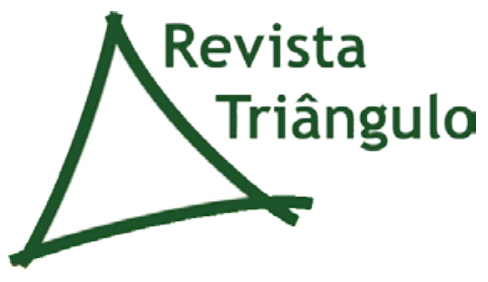

Uberaba, v. 5, n. 2, p. 22-44, jul./dez. 2012. ISSN: 2175-1609

tomada de posição pode refletir também a opinião da revista, do jornal ou outro meio. Quem apresenta essa afirmação nova é um ser animado, humano ou humanizado;

- toda charge possui um objeto animado, humano ou humanizado, que colabora para a construção da argumentação (Fig. 3). Esse objeto animado pode se associar (interagir) com os estágios opcionais da charge - cenário, personalidade - e com seus estágios recursivos - balão, onomatopéia, linhas e traços ${ }^{7}$.

Figura 3: Charge como produto de retextualização

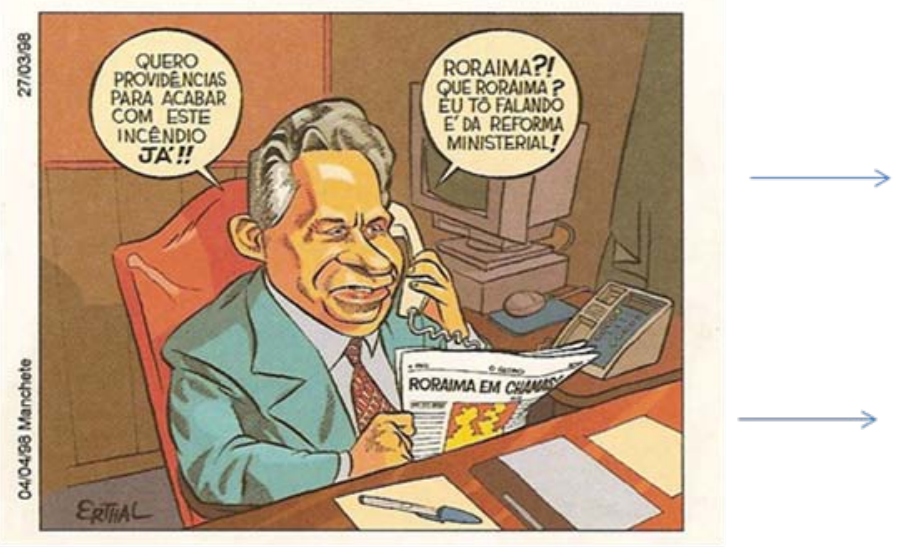

A charge se originou das noticias sobre o maior incêndio em Roraima já registrado (1998).

\section{(Ver DGE, 2010, on line)}

Aqui o chargista retrata o dilema governamental: o que é mais importante resolver 0 desastre ambiental de Roraima ou realizar a reforma ministerial?

Fonte: ERTHAL, 1998, p. 52.

Todo objeto animado se constituirá, portanto, de: (a) planos de visão ${ }^{8}$ - plano americano, plano médio ou aproximado e primeiro plano; (b) ângulos de visão - médio, superior e inferior.

- Geralmente, a notícia escolhida para retextualização em charge é uma notícia de cunho político ou social que, direta ou indiretamente, pode afetar a vida de qualquer cidadão comum.

\footnotetext{
${ }^{7}$ Para melhor compreensão dos termos em destaque pertencentes à linguagem dos quadrinhos, consultar Ramos (2007; 2009; 2011).

${ }^{8}$ Para mais detalhes sobre planos e ângulos de visão, consultar Ramos (2007; 2009; 2011).
} 


\section{Revista \\ Triângulo}

Figura 4: Objetos animados

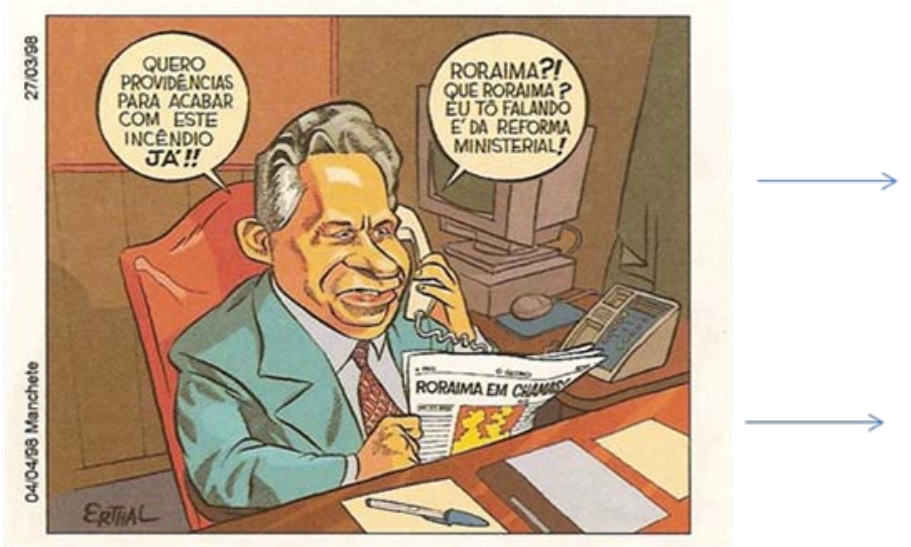

A charge se originou das noticias sobre o maior incêndio em Roraima já registrado (1998).

\section{(Ver DGE, 2010, on line)}

Aqui o chargista retrata o dilema governamental: o que é mais importante resolver o desastre ambiental de Roraima ou realizar a reforma ministerial?

Fonte: ERTHAL, 1998, p. 52.

O segundo elemento obrigatório, a data de veiculação, tem por finalidade contribuir para a identificação das notícias jornalísticas que foram base para a elaboração das charges. Dentre as características desse estágio, temos que:

- apresenta elementos temporais (dia, mês, ano) que podem surgir em lugares variados, mas sempre de forma discreta e que, quando omissos, são retomados por algum outro elemento;

- não se apresentam de forma cartunizada;

- pode receber o nome da revista ou jornal em que foi editada. Quando isso ocorre, normalmente há a divulgação de duas datas: uma relativa à primeira e outra relativa à segunda publicação (Fig. 5). 


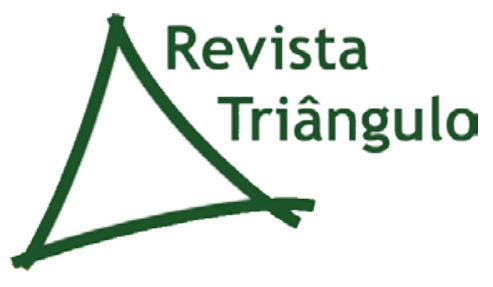

Uberaba, v. 5, n. 2, p. 22-44, jul./dez. 2012. ISSN: 2175-1609

Figura 5: Data de veiculação

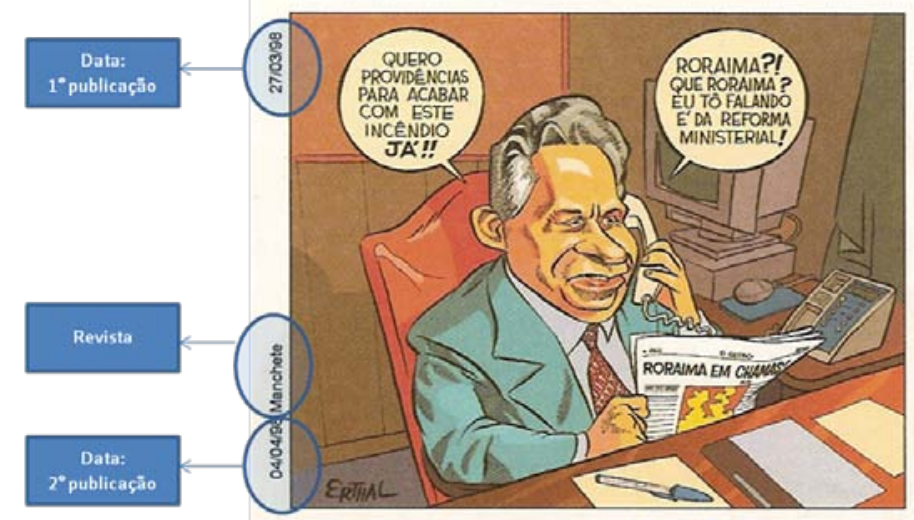

Fonte: ERTHAL, 1998, p. 52.

O terceiro elemento obrigatório, a assinatura autoral, tem por finalidade demarcar a autoria da charge. Dentre as características desse estágio temos que a charge:

- surge cartunizada de modo característico (Fig. 6);

- não possui um lugar fixo de aparecimento. Entretanto, há uma certa recorrência embaixo, à direita ou à esquerda.

Figura 6: Assinatura autoral
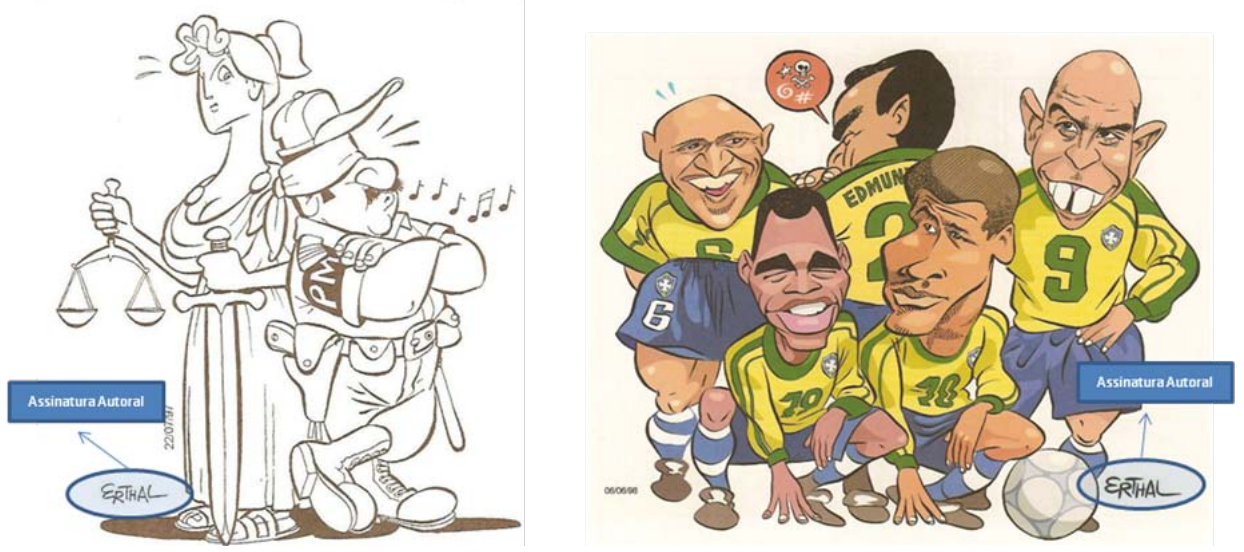

Fonte: ERTHAL, 1998, p. 31 e p. 69 


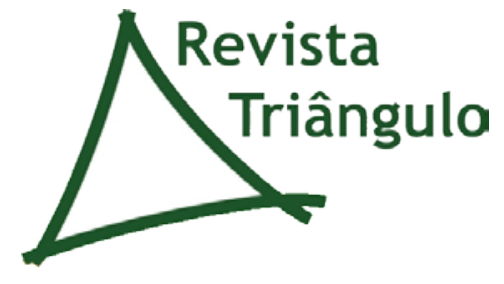

Uberaba, v. 5, n. 2, p. 22-44, jul./dez. 2012. ISSN: 2175-1609

Tecidas nossas considerações sobre a Estrutura Potencial do Gênero (EPG) charge, enfatizando principalmente os estágios obrigatórios definitórios do gênero (Cf. HASAN, 1989; 2005), passaremos, a seguir, à apresentação de nossas estratégias de ensino de língua portuguesa com o gênero charge.

\section{ESTRATÉgIAS DE ENSINO DE LÍNGUA PORTUGUESA COM O GÊNERO CHARGE}

\subsection{REFLEXÕES INICIAIS}

Para construir as estratégias abaixo (próxima seção), expostas em forma de exercícios, nos pautamos nas reflexões pedagógicas e sistêmico-funcionais de Vian Jr. (2006) e Vian Jr. \& Ikeda (2009). A fim de construir breves cadernos didáticos e/ou listas de exercícios sobre o ensino de língua portuguesa e os gêneros do discurso, nos inspiraram também as proposições didáticas de Machado, Lousada e Abreu-Tardelli (2004a, 2004b, 2005, 2007).

O primeiro aspecto a se considerar é que as estratégias de ensino propostas para os gêneros multimodais, no nosso caso, o gênero charge, privilegiaram a compreensão não só do texto, mas do gênero e do texto, juntamente com seus aspectos verbais e não verbais. Essas estratégias, portanto, são aplicáveis às práticas pedagógicas do professor de ensino médio e/ou português instrumental, desde que este reflita e considere como afirmativas as resposta das seguintes questões:

(1) Eu, enquanto pesquisador, sei trabalhar, ainda que minimamente, com os conceitos que subjazem à proposta teórico-pedagógica que levarei para a sala de aula?

(2) Eu, enquanto professor, tenho afinidade e/ou práticas de leitura e escrita desse gênero?

(3) Os meus alunos têm algum tipo de interesse, curiosidade ou algum objetivo em ler ou produzir esse gênero que escolhi para instrumentalizar os conteúdos de língua portuguesa? 


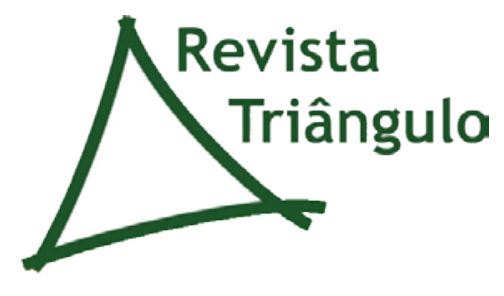

Uberaba, v. 5, n. 2, p. 22-44, jul./dez. 2012. ISSN: 2175-1609

(4) Os conteúdos programáticos indicados para a disciplina que ministro em sala de aula permitem que eu, enquanto professor, leve esse gênero para a sala de aula?

É por meio dessa reflexão crítica que a pertinência de nossas atividades pode ou não ser encaminhada para a sala de aula. De forma alguma queremos aqui induzir que agora os melhores textos para se trabalhar o ensino de língua portuguesa sejam os multimodais, ou os textos que apresentam a linguagem dos quadrinhos. Como acreditamos, a escolha dos textos e das práticas pedagógicas do professor devem se pautar em sua formação acadêmica (teoria) e em suas vivências profissionais (prática). É dessa complexa relação que surgirão os elementos necessários para que o professor escolha, utilize e elabore suas próprias estratégias de ensino.

Outro aspecto a se considerar é a utilização de alguns conceitos linguísticos que pertencem ao campo de estudo dos gêneros discursivos. Como orienta Vian Jr. (2006), deve-se evitar o uso de jargões tecnicistas e demasiado teóricos em sala de aula. Como sabemos, aspectos da teoria devem ter maior relevância quando travamos discussões essencialmente teóricas (nos cursos de Letras, em cursos de mestrado e doutorado). Por isso mesmo, na prática de ensino básico (médio) e/ou instrumental, alguns conceitos, o que é natural, podem e devem ser adaptados e/ou suprimidos, a fim de não causar incompreensões. O professor, entretanto, deve saber com precisão a base teórica que foi utilizada, adaptada e/ou suprimida na prática pedagógica utilizada. $\mathrm{O}$ aluno pode não saber o que fundamenta o exercício desenvolvido por ele, mas cabe ao professor conhecer as bases teóricas do que leva para a sala de aula a fim de somente agregar à sua prática profissional exercícios e teorias que dialoguem de alguma forma com a sua formação acadêmica.

Feitas essas colocações, indicamos que os exercícios que apresentaremos necessitam previamente da explicação de alguns conceitos da teoria de gêneros ${ }^{9}$, tais como: texto, gênero textual, tipo textual e suporte. Dito de forma simples, temos que:

\footnotetext{
${ }^{9}$ Salientamos aqui que, como a charge utiliza a linguagem dos quadrinhos, é preciso também que o professor explique aos alunos essa linguagem (Cf. RAMOS, 2007; 2009; 2011). 


\section{$\triangle$}

Uberaba, v. 5, n. 2, p. 22-44, jul./dez. 2012. ISSN: 2175-1609

- Texto é uma construção textual significativa em um dado contexto. Ele é composto de coesão, coerência e demais componentes da textualidade.

- Gênero textual ${ }^{10}$ é um texto nomeado na sociedade e que possui um conjunto de características que lhe são próprias, um propósito social (objetivo) e, de forma geral, representa o que de fato as pessoas fazem na sociedade.

- Tipo textual são sequências de palavras que indicam movimentos textuais característicos, tais como os tipos textuais: narrar, descrever e argumentar.

- Suporte é aquilo que suporta, mostra ou fixa o gênero textual no mundo.

Diante desses conceitos, podemos dizer que todo texto, além de ser um texto (por significar, possuir coesão, coerência e demais componentes da textualidade), é um gênero textual, pois possui, na maioria das vezes, um nome sob o qual é reconhecido e um conjunto de características que lhe são próprias - dentre elas o predomínio de um ou mais tipos textuais. Sendo assim, uma entrevista, por exemplo, é um texto, mas além de ser texto é também um gênero textual, pois é nomeado socialmente, possui um propósito social e, como característica básica, no caso, a estrutura marcada por pergunta e resposta. Esse gênero entrevista, portanto, possui essas características, pois foi construído em um contexto bastante particular.

Tendo exposto e ficado claros os conceitos acima, passaremos a seguir a apresentar as estratégias de ensino de língua portuguesa com o gênero multimodal charge.

\subsection{PROPOSIÇÕES DIDÁTICAS}

Para iniciarmos as nossas estratégias, a título de introdução ao assunto, uma vez já explicados os conceitos de texto, gênero, tipo textual, suporte e linguagem dos quadrinhos, sugerimos aos alunos a resolução do seguinte questionário (Fig. 7):

\footnotetext{
${ }^{10}$ A fim de facilitar a compreensão do que vem a ser gênero, optamos, como também o faz Meurer (HERBELE, 2011), por utilizar a expressão "gênero textual” ao invés de "gênero discursivo”, uma vez que a expressão “gênero textual” é mais difundida nos livros didáticos e demais produções pedagógicas, embora saibamos que a LSF trabalhe com o termo "gênero discursivo". Aqui, então, a fim de facilitar a construção das proposições didáticas, optamos pelo termo gênero textual.
} 


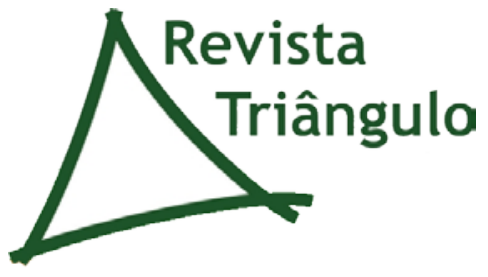

Uberaba, v. 5, n. 2, p. 22-44, jul./dez. 2012. ISSN: 2175-1609

Figura 7: Orientações para pesquisa sobre a charge

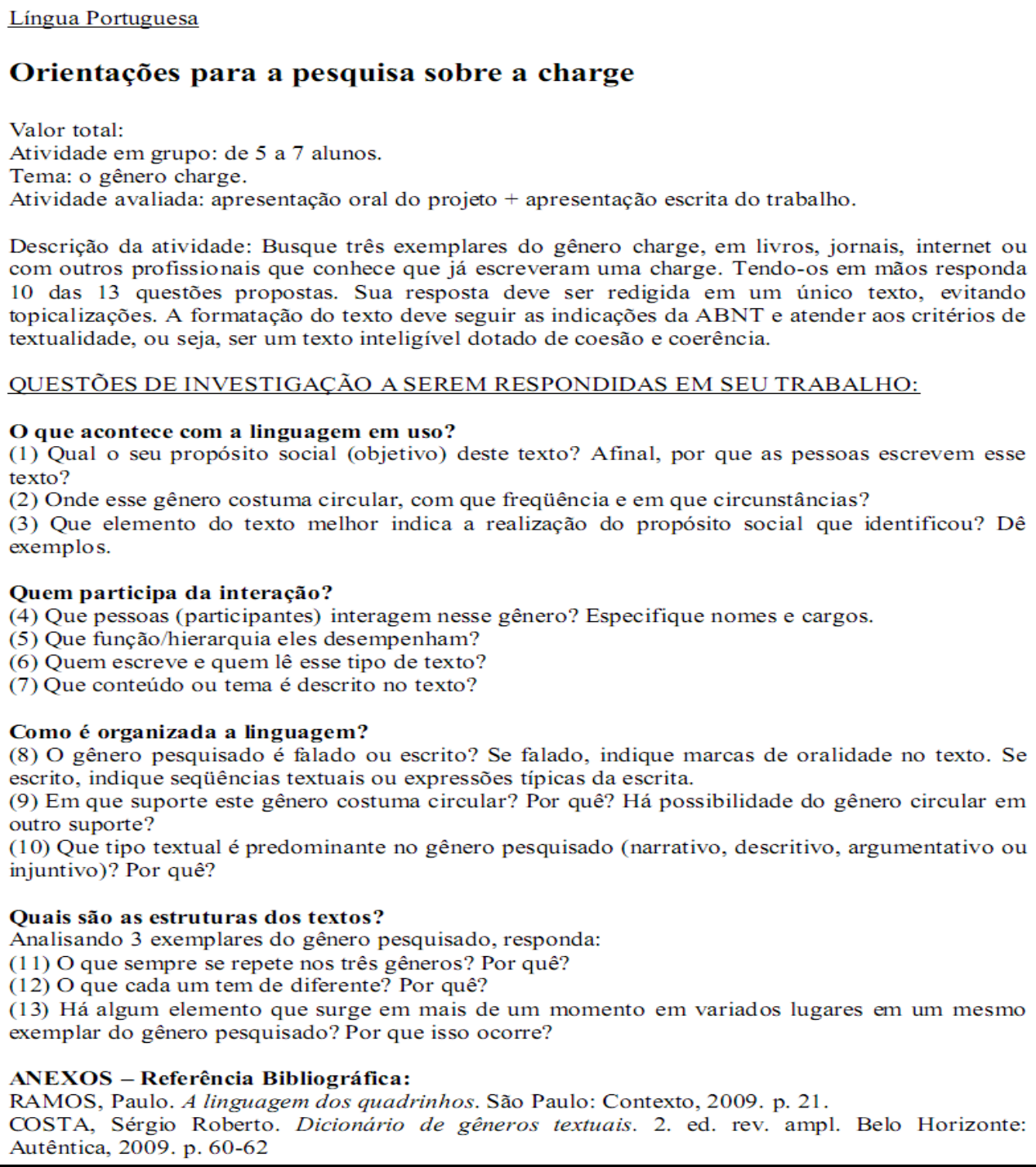

(8) O gênero pesquisado é falado ou escrito? Se falado, indique marcas de oralidade no texto. Se escrito, indique seqüências textuais ou expressões típicas da escrita.

(9) Em que suporte este gênero costuma circular? Por quê? Há possibilidade do gênero circular em outro suporte?

(10) Que tipo textual é predominante no gênero pesquisado (narrativo, descritivo, argumentativo ou injuntivo)? Por quê?

Quais são as estruturas dos textos?

Analisando 3 exemplares do gênero pesquisado, responda:

(11) O que sempre se repete nos três gêneros? Por quê?

(12) O que cada um tem de diferente? Por quê?

(13) Há algum elemento que surge em mais de um momento em variados lugares em um mesmo exemplar do gênero pesquisado? Por que isso ocorre?

ANEXOS - Referência Bibliográfica:

RAMOS, Paulo. A linguagem dos quadrinhos. São Paulo: Contexto, 2009. p. 21.

COSTA, Sérgio Roberto. Dicionário de gêneros textuais. 2. ed. rev. ampl. Belo Horizonte: Autêntica, 2009. p. 60-62

Fonte: os autores

Esse questionário-pesquisa levará os alunos a identificar o contexto de produção do gênero charge, observando a real prática social por trás do texto conhecido como charge, além de, ao final, estimulá-los a escrever suas conclusões em um texto coeso, coerente, em forma de trabalho escolar e/ou acadêmico. A fim de auxiliar os alunos na busca de exemplares do gênero charge, foram inseridas nas orientações de pesquisa, no item Anexos, duas definições do termo 


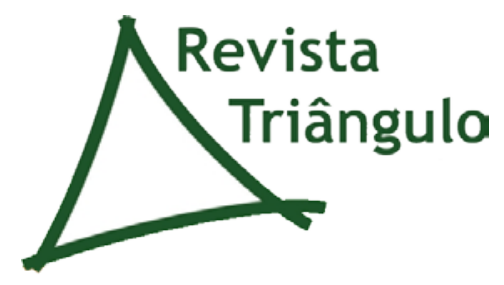

Uberaba, v. 5, n. 2, p. 22-44, jul./dez. 2012. ISSN: 2175-1609

charge. A primeira definição está contida no Dicionário de gêneros textuais, de Sérgio Roberto da Costa (2009), e a outra é descrita por Paulo Ramos (2009), no livro A linguagem dos quadrinhos.

As últimas questões de pesquisa do questionário de investigação requerem a observação de exemplares do gênero charge. Nesse item, o professor pode já indicar previamente três charges ou permitir que os alunos tragam por livre pesquisa seus próprios exemplares.

Feitas as atividades introdutórias do estudo do gênero charge, passamos agora a descrever as nossas estratégias de língua portuguesa com o referido gênero. Essas estratégias, como destacamos na configuração da estrutura potencial do gênero (EPG) charge, devem enfocar os estágios obrigatórios do gênero (Cf. HASAN, 1989; 2005), pois são esses estágios que definem a charge como o gênero charge. É aconselhado que os exemplares-base dos exercícios apresentados sejam configurados pelos instrumentos teórico-metodológicos da Estrutura Potencial do Gênero (EPG), de Hasan (1989; 2005). É a EPG, portanto, que dará ao professor a visão potencial do gênero. A EPG é como se fosse o DNA do gênero, como diria Ramos (2011), ao se referir à teoria sistêmico-funcional de Hasan. Com ela visualizar-se-á tudo o que pode ocorrer com o texto inserido em um determinado contexto. A Estrutura Potencial do Gênero (EPG) charge deve ser apresentada aos alunos, a fim de que eles possam observar a influência do contexto para as estruturas do texto. Essa exposição deve ser breve e tomar como ponto de discussão um ou dois exemplares do corpus de análise. Dessa forma, apresentam-se em alguns exemplares do corpus analisado os elementos obrigatórios, opcionais e recursivos.

Demonstrada a Estrutura Potencial do Gênero (EPG), apresentamos, ao final da proposição didática, um exercício de fixação. Esse exercício, em virtude da formatação deste artigo, será inserido na seção Anexos.

O primeiro exercício apresentado (ver Anexo) busca mapear o contexto geral de realização da charge na sociedade, o que se aproxima do que a teoria sistêmico-funcional chama de campo. Os alunos descreverão, então, o que sabem sobre a charge ou o que puderam aprender com a pesquisa e as aulas dirigidas sobre o gênero. Em seguida, os alunos, na questão 2 (ver Anexo), são levados a identificar o gênero charge em meio a outros gêneros dos quadrinhos (Cf. RAMOS, 2007; 2009; 2011). Identificado que exemplar de texto é a charge, os alunos passam à 


\section{$\underbrace{\text { Revista }}_{\text {Triângulo }}$}

Uberaba, v. 5, n. 2, p. 22-44, jul./dez. 2012. ISSN: 2175-1609

questão seguinte, questão 3, que visa compreender um pouco mais sobre a charge ao levar os alunos a ler a linguagem verbal e a não verbal do texto analisado.

A última questão (ver Anexo), a questão 4, é bastante aberta e espera que os alunos possam escolher um texto e seguir com a sua leitura e compreensão. Nessa questão, subdividida nos subitens 4.1, 4.2, 4.3 e 4.4, os alunos poderão analisar o gênero em suas especificidades em relação ao texto (leitura verbal e não verbal) e em relação ao gênero (prática social).

Tendo sido apresentadas, nesta seção, as estratégias de ensino de língua portuguesa a partir do gênero charge, passemos, na seção final, às nossas considerações finais sobre o assunto.

\section{CONSIDERAÇÕES FINAIS: IMPLICAÇÕES E ALCANCES DE NOSSAS PROPOSIÇÕES DIDÁTICAS}

Em nossa exposição, vimos que atualmente o ensino de língua portuguesa tem se direcionado para o ensino do texto em sala de aula, materializado em algum gênero do discurso. Essa postulação, portanto, tem instigado pesquisadores das mais diversas áreas de estudo do objeto a investigar a questão: como levar os gêneros discursivos para a sala de aula? Instigados por essa questão, pesquisadores ainda têm se indagado sobre como utilizar os gêneros

multimodais como objeto de ensino das aulas de língua portuguesa. Afinal, que tipo de estratégias, teorias e métodos podem ser utilizados nessa tarefa? 


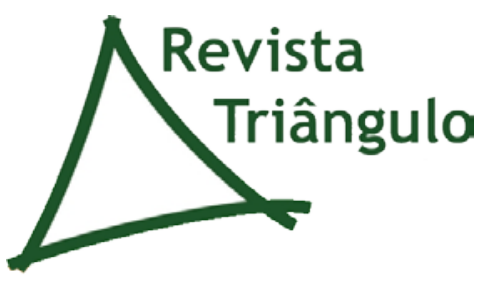

Uberaba, v. 5, n. 2, p. 22-44, jul./dez. 2012. ISSN: 2175-1609

Diante dessas questões, apresentamos aqui a teoria sistêmico-funcional proposta por Hasan (1989; 2005) como forma de instrumentalizar os professores de línguas para o trabalho com os gêneros em sala de aula. Para a autora (1989; 2005), por meio das singularidades do contexto, podemos prever os elementos da estrutura de um texto, ou seja, seus estágios obrigatórios, opcionais e iterativos (ou recursivos). Foi nesse sentido que resgatamos a configuração do gênero charge realizada por Simões (2010) em sua dissertação de mestrado. Dessa configuração, concluímos que a charge, ao menos em nosso corpus de estudo -composto por 20 charges do livro Fatores de risco, do chargista Júlio Erthal -, é configurada pelos estágios obrigatórios: retextualização de uma notícia jornalística, data de veiculação e assinatura autoral. Figura 8: A configuração do gênero charge

Fonte: SIMÕES, 2010, p. 131

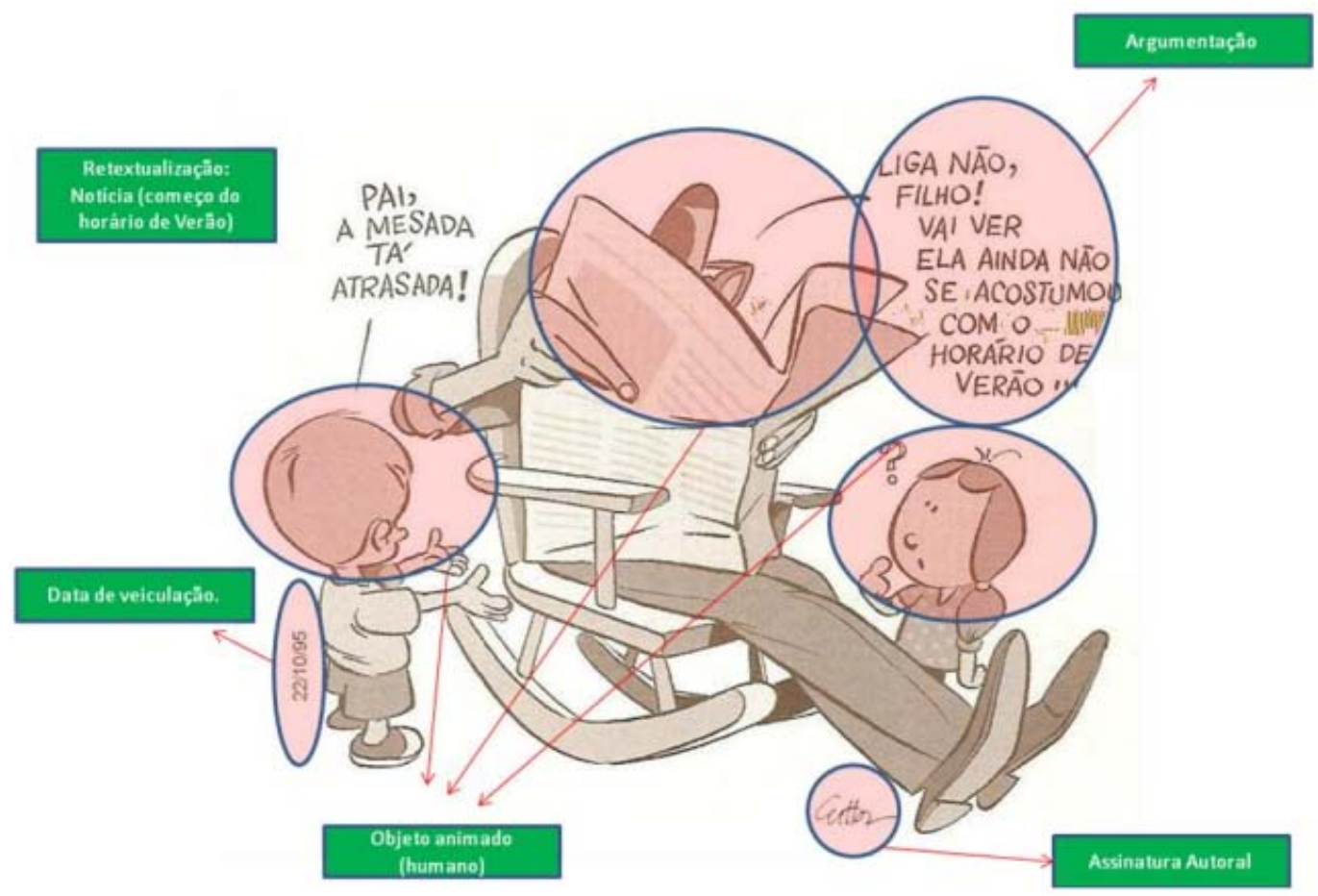




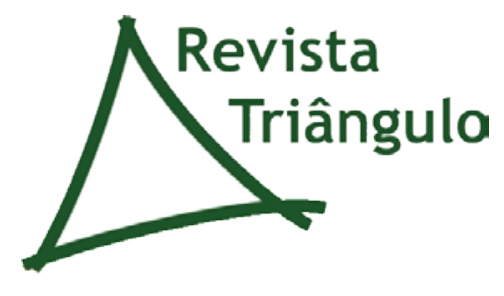

Uberaba, v. 5, n. 2, p. 22-44, jul./dez. 2012. ISSN: 2175-1609

Há ainda estágios opcionais (título, cor, intergenericidade, sargeta, requadro, cenário e seriação) e recursivos (balão, onomatopéia, e linhas e traços) (Fig. 8).

Ao configurarmos o gênero charge, descobrimos sua potencialidade enquanto texto. A teoria sistêmico-funcional de análise de gêneros (Cf. HASAN, 1989; 2005), por si só, já indica ao professor o que ensinar do gênero (seus estágios obrigatórios) e como ensinar (apresentando a Estrutura Potencial do Gênero aos alunos), desde, é claro, que sejam explicados para os alunos, de forma simples e breve, alguns conceitos-chave para o entendimento da teoria sistêmica e/ou de gêneros. No que se refere à multimodalidade, descobrimos ainda que a teorização de Hasan (1989; 2005), embora idealizada para a análise de textos verbais, também é capaz de analisar textos não verbais, ao menos textos não verbais já codificados pelos estudos da linguagem, como é o caso da linguagem dos quadrinhos (Cf. RAMOS, 2007; 2009; 2011). Apesar disso, acreditamos que outras linguagens ainda necessitem ser investigadas, a fim de viabilizar sua possível articulação com a teoria potencial de Hasan. Seria, por exemplo, a linguagem publicitária (a não verbal), significativa o suficiente para a teoria sistêmico-funcional de Hasan (1989; 2005) analisar? Seria ela, com sua plasticidade característica, objeto de configuração da Estrutura Potencial do Gênero? Ao que nos parece, os gêneros dos quadrinhos, como textos multimodais, possuem natureza mais visual do que verbal. Isso reflete a natureza da Estrutura Potencial do Gênero Charge (EPG) que configuramos. Sendo assim, podemos inferir que todo texto, embora multimodal, tem a sua natureza mais focada em um modo semiótico do que em outro. Esse fato, como acreditamos, deve ser levando em consideração ao escolher esse tipo de texto para atividades em sala de aula.

Deixando as questões acima para futuras pesquisas, em nossa exposição, a partir das teorizações da autora (1989; 2005), pudemos entender o gênero charge e o que dele deve ser enfatizado nas práticas de ensino-aprendizagem. Tendo ficado claro esse aspecto, construímos duas proposições didáticas para o ensino de língua portuguesa que utilizam o gênero charge. A primeira proposição foi idealizada para ser realizada antes da exposição da Estrutura Potencial do Gênero (EPG). Ela nada mais é do que um roteiro de pesquisa que introduz o aluno ao estudo do gênero charge, partindo da definição do termo, de seu contexto de situação e da análise livre de 


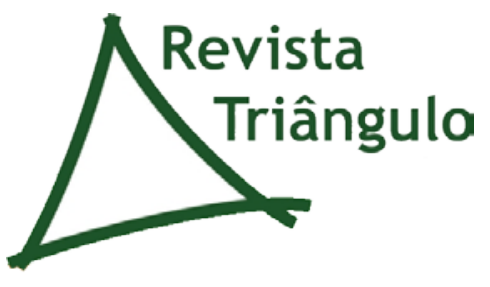

Uberaba, v. 5, n. 2, p. 22-44, jul./dez. 2012. ISSN: 2175-1609

exemplares prototípicos do gênero. Há perguntas gerais sobre o funcionamento e significado do texto conhecido como charge. Os alunos respondem às questões e, como forma de treinar a produção de textos, na oralidade e escrita, são convidados a apresentar suas conclusões sobre a charge em breves seminários, como mostra o roteiro de pesquisa do gênero.

A segunda proposição didática foi idealizada para ser realizada após a exposição da Estrutura Potencial do Gênero (EPG) charge. Nela há exercícios que buscam levar os alunos a nomear o gênero, diferenciá-lo diante de gêneros semelhantes e a entendê-lo do ponto de vista de sua prática social, visualizando seu propósito social, suas partes, funções e demais significações pertinentes ao texto e ao gênero.

Dessa forma, nossa proposição didática para o ensino de língua portuguesa com o gênero charge pode ser resumida pelos seguintes passos (Fig. 9):

Figura 9: Proposição didática para o ensino de língua portuguesa com o gênero charge

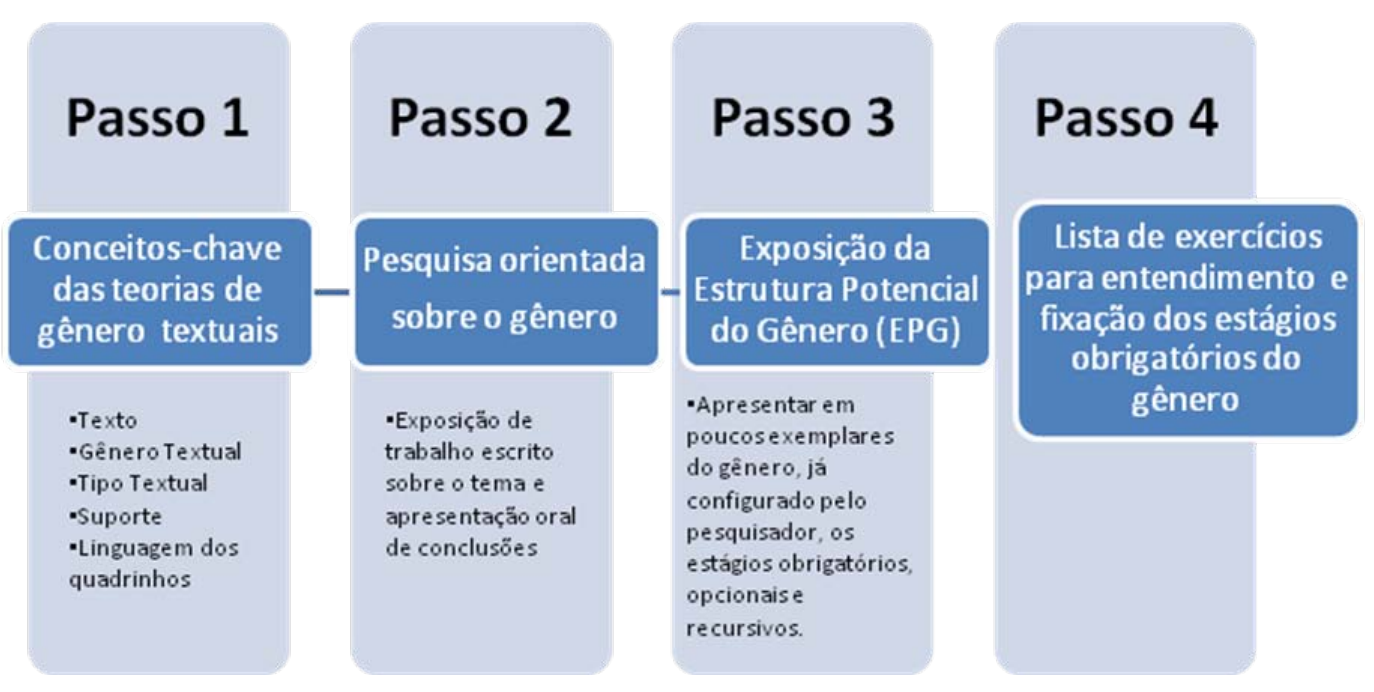

Fonte: Os autores 


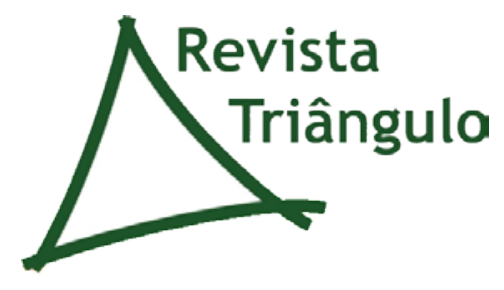

Uberaba, v. 5, n. 2, p. 22-44, jul./dez. 2012. ISSN: 2175-1609

Nossa proposição didática, apesar de ser idealizada para o gênero charge, nos parece possível de ser aplicada a outros gêneros e situações. Ele consiste na apresentação de conceitoschave da teoria de gêneros para os alunos; na pesquisa orientada sobre o gênero, por meio de um roteiro de perguntas direcionado; na exposição simplificada da Estrutura Potencial do Gênero (EPG); e na resolução de exercícios que fixem o entendimento dos estágios obrigatórios do gênero.

Podemos dizer ainda que propostas didáticas como essa são escassas, ainda mais pautadas nas postulações de gênero de Hasan (1989; 2005). Cadernos didáticos e/ou exercícios que trabalhem o gênero em sala de aula também são pouco vistos no mercado editorial e/ou científico, ainda mais quando há textos multimodais, como é o caso dos gêneros dos quadrinhos (Cf. RAMOS, 2007; 2009; 2011).

Dessa forma, nossa exposição se mostra relevante, produtiva e bastante prática para professores, alunos e demais estudantes dos cursos de Letras, Artes e afins. Ela, no futuro, o que é natural, deve ser revista e adequada a novas situações e/ou sugestões. De nossa parte, ficamos por aqui certos de termos fomentado novas ideias e novas experimentações pedagógicas para o ensino de línguas e os gêneros multimodais.

\section{REFERÊNCIAS}

AMARAL, L. Técnica de Jornal e Periódico. 4. ed. Rio de Janeiro: Tempo Brasileiro, 1978.

BOWCHER, W. L. Field and multimodal texts. In: HASAN, R.; MATHIESSEN, C.; WEBSTER, J. Continuing Discourse on language: a functional perspective. v. 2. Equinox, 2007. p. 619-646.

BRASIL. Ministério da Educação e do Desporto. 1998. Parâmetros Curriculares Nacionais.

COSTA, S. R. Dicionário de gêneros textuais. 2. ed. rev. ampl. Belo Horizonte: Autêntica, 2009.

DELL’ISOLA, R. L. P. Retextualização de gêneros escritos. Rio de Janeiro: Lucerna, 2007.

EGGINS, S. An introduction to systemic funtional linguistics. London: Pinter Publishers, 1994. p. 25-80. 


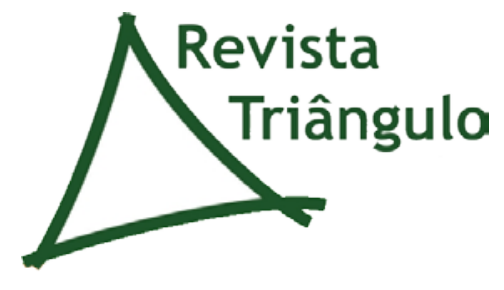

Uberaba, v. 5, n. 2, p. 22-44, jul./dez. 2012. ISSN: 2175-1609

ERTHAL, J. Fatores de Risco. Rio de Janeiro: Ediouro, 1998.

HASAN, R. Language and society in a systemic functional perspective. In: HASAN, R; MATTHIESSEN, C; WEBSTER, J. J. Continuing Discourse on Language. London: Equinox Publishing LTD, 2005. p. 55-78.

HASAN, R. The structure of a text the identity of text. In: HALLIDAY, M. A. K.; HASAN, R. Language, context and text: aspects of language in a social-semiotic perspective. Oxford: Oxford University press, 1989.

HERBELE, V. M. Texto, discurso, gêneros textuais e práticas sociais na sociedade contemporânea: tributo a José Luiz Meurer. Cadernos de Linguagem e Sociedade, 12 (1), p. 155168, 2011.

MACHADO, A. R; LOUSADA, E; ABREU-TARDELLI, L. S. Planejar gêneros acadêmicos. São Paulo: Parábola, 2005.

MACHADO, A. R; LOUSADA, E; ABREU-TARDELLI, L. S. Resenha. São Paulo: Parábola, 2004b.

MACHADO, A. R; LOUSADA, E; ABREU-TARDELLI, L. S. Resumo. São Paulo: Parábola, 2004a.

MACHADO, A. R; LOUSADA, E; ABREU-TARDELLI, L. S. Trabalhos de pesquisa: diários de leitura para a revisão bibliográfica. 2. reimp. São Paulo: Parábola, 2007.

RAMOS, P. A leitura dos quadrinhos. São Paulo: Contexto, 2009.

RAMOS, P. Faces do humor: uma aproximação entre piadas e tiras. Campinas, SP: Zarabatana Books, 2011.

RAMOS, P. Tiras cômicas e piadas: duas leituras, um efeito de humor. Tese (doutorado). USP, São Paulo: 2007.

SIMÕES, A. C. A configuração de gêneros multimodais: um estudo sobre a relação gênerosuporte nos gêneros discursivos tira cômica, cartum, charge e caricatura. Viçosa, 2010. 140f. Dissertação (Mestrado em Letras). Universidade Federal de Viçosa.

SIMÕES, A. C. A configuração do gênero caricatura: uma abordagem sistêmico-funcional. Revista Prolíngua. v. 6, n. 2, Jan./Jun, 2011. 


\section{Revista Triângulo}

SOARES, M. Prefácio. In: COSTA, S. R. Dicionário de gêneros textuais. 2.ed. rev. ampl. Belo Horizonte: Autêntica Editora, 2009. p. 7-9.

VIAN JR. Gêneros discursivos e conhecimento sobre gêneros no planejamento de um curso de português instrumental para ciências contábeis. In: Linguagem em (Dis)curso - LemD, Tubarão, v. 6, n. 3, p. 389-411, set./dez, 2006.

VIAN JR., O; IKEDA, S. N. O ensino do gênero resenha pela abordagem sistêmico-funcional na formação de professores. In: Linguagem \& Ensino, Pelotas, v.12, n.1, p. 13-32, jan./jun, 2009. 